\title{
CARACTERIZAÇÃo FÍSICA E MECÂNICA DE ARGAMASSAS À BASE DE CIMENTO PORTLAND E CINZA DE CASCA DE ARROZ RESIDUAL
}

\author{
MICHELLE S. RODRIGUES ${ }^{1}$, ANTONIO L. BERALDO ${ }^{2}$
}

\begin{abstract}
RESUMO: A casca de arroz, utilizada como fonte de energia em indústrias de beneficiamento de arroz, converte-se, depois da queima, em uma cinza residual. Esse resíduo, ainda sem um destino adequado, é muitas vezes depositado em grandes áreas abertas e provoca elevado impacto ambiental. Este trabalho teve como objetivo avaliar a viabilidade de utilização da cinza de casca de arroz (CCA) residual na produção de argamassas, como substituta parcial do cimento. A caracterização da CCA foi realizada por meio da análise de fluorescência de raios-X (composição química), análise do teor de carbono e difração de raios-X; também foi realizada análise granulométrica a laser. Os corpos de prova foram submetidos a dois tipos de exposição: ambientes externo e interno, com duração máxima de cinco meses. Foram realizados os ensaios de resistência à compressão simples e não destrutivo (velocidade do pulso ultrassônico - VPU). Embora as argamassas tenham apresentado bom desempenho mecânico, os ensaios de pozolanicidade indicaram que a cinza de casca de arroz residual utilizada não é uma pozolana, mas pode ser utilizada em matrizes cimentícias como material inerte (filler).
\end{abstract}

PALAVRAS-CHAVE: cimento Portland, cinza de casca de arroz (CCA), argamassa.

\section{PHYSICAL AND MECHANICAL CHARACTERIZATION ON PORTLAND CEMENT MORTAR WITH RICE HUSK ASH ADDITION}

\begin{abstract}
Rice husk, employed as an energy source at milling industries in Brazil generates, after burning, a dark ash. This residue is not yet conveniently disposed, being currently dumped on large areas, causing environmental problems. This research intended to evaluate the applications of residual rice husk ashes (RHA) as a partial replacement of cement for mortar production. Rice husk ash was chemically characterized through X-ray fluorescence, determination of carbon content, Xray diffraction, and laser granulometric analysis. Mortar specimens were submitted to two different exposure conditions: internal and external environments at a maximum period of five months. Physical-mechanical testing were compressive strength and ultrasonic pulse velocity (UPV). Although presenting good mechanical performance, the mortar based on ash (RHA) did not present pozolanicity but it can be employed in cement matrices as inert material (filler).
\end{abstract}

KEYWORDS: Portland cement, residual rice hush ash (RHA), mortar.

\section{INTRODUÇÃO}

O Brasil situa-se entre os grandes produtores mundiais de arroz, com uma produção anual em torno de 11,5 milhões de toneladas (IBGE-2007). No ano de 2007, no Estado de São Paulo, a produção foi de 82.800 toneladas de arroz, representando apenas $0,7 \%$ da produção nacional. Porém, parte do arroz produzido nacionalmente é beneficiado em São Paulo, gerando resíduos com baixa densidade e grande volume.

Em razão do seu alto poder calorífico $\left(\sim 16.720 \mathrm{~kJ} \mathrm{~kg}^{-1}\right)$ e do baixo custo, a casca de arroz vem, cada vez mais, substituindo a lenha empregada na geração de calor e vapor, necessários para os processos de secagem e parboilização dos grãos de arroz (DELLA et al., 2001). A cinza que é gerada nesse processo, por sua vez, promove a poluição no solo, pois apresenta uma quantidade de

\footnotetext{
${ }^{1}$ Doutoranda, Faculdade de Engenharia Agrícola, Universidade Estadual de Campinas, Campinas - SP, michatcsr@yahoo.com.br. ${ }^{2}$ Prof. Associado, Faculdade de Engenharia Agrícola, Universidade Estadual de Campinas, Campinas - SP, beraldo@agr.unicamp.br. Recebido pelo Conselho Editorial em: 21-5-2008 Aprovado pelo Conselho Editorial em: 4-11-2009
} 
carbono residual, além da concentração de óxidos alcalinizantes $\left(\mathrm{CaO}, \mathrm{MgO}, \mathrm{K}_{2} \mathrm{O}, \mathrm{Na}_{2} \mathrm{O}\right.$, entre outros) os quais, ao entrar em contato com a água, alcalinizam o meio aquoso (ZUCCO, 2007).

O uso da cinza de casca de arroz (CCA) em concreto foi patenteado no ano de 1924 e, após 1972, muitos pesquisadores concentraram-se na utilização da CCA derivada de queima não controlada (NAIR et al., 2006). A partir daí, diversas pesquisas têm sido realizadas com o uso da CCA em matrizes cimentícias, tanto para cinzas produzidas com queima controlada, quanto aquela à base de cinza de casca de arroz residual, obtida no processo de beneficiamento de arroz.

Para a obtenção de CCA reativa, MEHTA \& MONTEIRO (1994) recomendaram que a temperatura de calcinação variasse entre $500{ }^{\circ} \mathrm{C}$ e $700{ }^{\circ} \mathrm{C}$, com duração tal que ocorresse a remoção completa do material orgânico.

A atividade pozolânica da CCA é caracterizada pela capacidade da sílica (em estado amorfo), presente em misturas com cimento ou cal, solubilizar-se no meio alcalino, reagindo em solução com os íons de cálcio, liberados nas reações de hidratação do cimento, formando compostos estáveis (monossilicatos de cálcio) dotados de poder aglomerante (silicatos e aluminatos de cálcio). Assim, quanto maior for a quantidade de sílica amorfa, maior será a possibilidade de obter-se melhoria na resistência da argamassa (MEHTA \& MONTEIRO, 1994).

Para avaliar a pozolanicidade de um material, faz-se necessário o uso de métodos químicos e/ou físico-mecânicos. Dentre eles, os mais adotados para avaliar a pozolanicidade de resíduos agroindustriais são os seguintes:

a) Análise química: para a realização dessa análise, um método espectroscópico bastante utilizado é a fluorescência de raios-X. O silício deve ser o elemento predominante em uma pozolana. CINCOTTO \& KAUPATEZ (1988) afirmaram que o teor mínimo de $\mathrm{SiO}_{2}$ nas pozolanas consideradas reativas é de $44 \%$. Alguns autores afirmaram que o teor máximo de carbono deva ser de 12\%; porém, MEHTA (1992) relatou o emprego de pozolanas com até $18 \%$ de carbono.

b) Finura: é muito importante caracterizar a finura do material empregado, pois material fino preenche os vazios, apresentando o efeito secundário de filler. A análise granulométrica a laser, ou até mesmo a estimativa grosseira por meio da fração retida na peneira \#200 (com abertura de malha $0,075 \mathrm{~mm})$, são alguns dos métodos utilizados. Recomenda-se que as partículas de pozolana apresentem superfície específica superior a $3.000 \mathrm{~cm}^{2} \mathrm{~g}^{-1}$ (JOHN et al., 2003).

c) Determinação do material vítreo: pode ser avaliada por meio da difração de raios-X. Esse método permite avaliar se o material é amorfo ou cristalino. Quanto mais cristalino for o material, menor será sua reatividade (JOHN et al., 2003).

d) Resistência mecânica: a NBR 5752 (1992) refere-se ao ensaio de mistura da pozolana com o cimento Portland, com o objetivo de avaliar seu potencial, como adição aos cimentos. A eficiência da pozolana é avaliada efetuando-se comparação entre a argamassa confeccionada apenas com cimento e aquela produzida tendo parte do cimento substituído por material supostamente pozolânico ( $65 \%$ de cimento e $35 \%$ de pozolana, em volume, proporção adotada segundo a NBR 5752 (ABNT, 1992)).

O objetivo deste trabalho foi o de pesquisar a produção de argamassas, com a substituição parcial do cimento pela CCA residual, com o intuito de diminuir o consumo de cimento nas matrizes cimentícias e aproveitar um resíduo que se encontra disponível na natureza, e que não tem uma destinação adequada na maioria das vezes. Também se buscou a melhor forma de aproveitamento desse resíduo, como material pozolânico ou como material inerte, na confecção de argamassas. Para isso, foram realizados estudos de caracterização química, física e mecânica da CCA e da argamassa com ela produzida, submetendo também a argamassa ao ensaio de durabilidade, para avaliar o comportamento desse material quando exposto às intempéries. 


\section{MATERIAL E MÉTODOS}

Para a produção de argamassas à base de cimento Portland e cinza de casca de arroz residual, foram utilizados os seguintes materiais:

Cimento Portland de alto forno (CPIII-RS-32): da marca Votoran, composto de $35 \%$ a $70 \%$ de escória de alto forno, de acordo com as especificações da NBR 5735 (ABNT, 1991). A superfície específica deste cimento é de $3.506 \mathrm{~cm}^{2} / \mathrm{g}$, e a massa específica real, de $3,09 \mathrm{~g} \mathrm{~cm}^{-3}$ (dados da empresa Votoran). Utilizou-se este tipo de cimento porque, em sua produção, ocorre menor emissão de $\mathrm{CO}_{2}$ na atmosfera, por ser composto de $35 \%$ a $70 \%$ de escória de alto forno.

Agregado mineral: foi utilizada areia fina natural proveniente de leito de rio. O módulo de finura desta areia é de 2,20, e a dimensão máxima, igual a 2,38 mm.

Cinza de casca de arroz residual (CCA): obtida na empresa Broto Legal, indústria de beneficiamento de arroz, localizada na cidade de Porto Ferreira - SP. Essa cinza foi gerada nos fornos da própria indústria, que utiliza a casca de arroz como fonte de energia nos processos de secagem do arroz. A temperatura e o tempo de queima não foram controlados, logo a cinza provém de queima irregular produzida na fornalha. Após o recebimento, a CCA residual utilizada passou por um processo de moagem, em um moinho de bolas, durante o período de $3 \mathrm{~h}$ (POUEY et al., 2007), com o intuito de diminuir a dimensão das suas partículas.

O programa experimental deste trabalho constituiu-se de três fases: caracterização da CCA residual, avaliação da pozolanicidade da CCA e produção das argamassas à base de cimento Portland e CCA residual, as quais foram submetidas a ensaios físicos e mecânicos.

\section{Caracterização da CCA residual}

Após a moagem da CCA residual, foi realizada a análise granulométrica do material, por meio da distribuição granulométrica por espalhamento de luz laser de baixo ângulo (Malvern). Buscou-se obter uma análise mais precisa do tamanho das partículas e também de sua superfície específica.

A composição química da cinza foi determinada por meio da análise de fluorescência de raios-X; a determinação do teor de carbono, com a queima da cinza a $1.500{ }^{\circ} \mathrm{C}$ foi efetuada em um analisador da marca Leco, modelo CS 125.

A caracterização mineralógica da CCA foi realizada por meio da técnica de difração de raios-X, em um difratômetro, da marca Philips, modelo MPD 1880. O ângulo de incidência dos raios-X na amostra é chamado de $2 \theta$ (dois teta), e o intervalo de medida entre os ângulos $2 \theta$ foi de $2,5^{\circ}$ a $50^{\circ}$. A identificação de fases cristalinas foi baseada na comparação do perfil determinado pelo ensaio com conjuntos de difrações-padrão, como os bancos de dados PDF2 do ICDD - International Centre for Diffraction Data (2003) e PAN-ICSD - PANanalytical Inorganic Crystal Structure Database (2007).

Esses ensaios de caracterização química fizeram-se necessários para avaliar-se a possibilidade de utilização da CCA residual, como material pozolânico ou como filler (efeito físico, de preenchimento de vazios).

\section{Avaliação da pozolanicidade da CCA residual}

Foi realizado o ensaio de materiais pozolânicos para mistura cimento-pozolana, de acordo com a norma NBR 5752 (ABNT, 1992).

Para esse ensaio, foram produzidas duas misturas, sendo que uma das argamassas era composta de $100 \%$ de cimento, areia e água (testemunha) e a outra era composta por $65 \%$ de cimento e 35\% de CCA (substituindo o volume equivalente de cimento), areia e água. A relação água/cimento foi de 0,5 para argamassa sem CCA e 0,55 para argamassa com CCA, ambas necessárias para produzir argamassas com índice de consistência de $(225 \pm 5) \mathrm{mm}$, segundo a NBR 7215 (ABNT, 1996). Para cada tipo de argamassa, foram confeccionados três corpos de prova 
cilíndricos de $50 \mathrm{~mm}$ (diâmetro) x 100 mm (altura), ensaiados à compressão aos 28 dias, confome norma NBR 7215 (ABNT, 1996).

A cura das argamassas foi realizada de acordo com a NBR 5752 (ABNT, 1992). Após a moldagem, os corpos de prova foram colocados em câmara úmida, durante período de 24 h, e após a desmoldagem, os mesmos foram colocados em recipientes fechados, durante o período de 27 dias. Após esse período, os corpos de prova foram retirados dos recipientes e foi realizado o capeamento e, em seguida, efetuou-se o ensaio de compressão simples (NBR 7215 - ABNT, 1996).

A possível eficiência dessa cinza como material pozolânico foi avaliada pela relação entre as resistências da argamassa-testemunha e aquela referente à substituição parcial do cimento pela CCA. A mistura deve apresentar resistência superior a $75 \%$ da resistência da argamassa de cimento Portland, segundo a NBR 5752 (ABNT, 1992).

\section{Produção das argamassas com CCA residual}

Para a produção de argamassas à base de cimento, areia natural e CCA residual, o cimento da mistura foi parcialmente substituído, em massa, pela cinza. As porcentagens de substituição adotadas foram de $5 \%, 10 \%, 15 \%$ e $20 \%$, e testemunha (sem a cinza). O traço adotado foi de 1:3:0,5 (cimento/cca: areia: água, em massa) para todas as argamassas, pois buscava-se a utilização do material na forma de argamassa de assentamento. Foram confeccionados seis corpos de prova para cada dosagem, para a realização dos ensaios.

As argamassas foram colocadas em moldes cilíndricos de $50 \mathrm{~mm}$ de diâmetro e $100 \mathrm{~mm}$ de altura, segundo a NBR 7215 (ABNT, 1996).

Os corpos de prova foram submetidos a ensaio não destrutivo e ensaio destrutivo de modo que se pudessem comparar as propriedades físico-mecânicas do material com CCA às do material sem cinza (testemunha). Após a desforma ( $24 \mathrm{~h}$ após a moldagem), os corpos de prova foram submetidos à cura úmida por sete dias, ficando os dias subsequentes sob cura ao ar livre.

\section{Exposição das argamassas}

Os corpos de prova ficaram expostos às intempéries e também foram colocados em ambiente interno no laboratório, para que fosse avaliado o efeito do ambiente de exposição no ensaio de envelhecimento natural (PIMENTEL, 2004). O tempo máximo de exposição foi de cinco meses. Foi produzida a mesma quantidade de corpos de prova para os dois tipos de exposição. Os períodos de exposição dos corpos de prova foram de 28 dias, quatro meses e cinco meses, tanto para os corpos de prova que ficaram expostos em bancadas (ambiente externo), quanto para aqueles que ficaram em ambiente interno.

Os corpos de prova expostos em ambiente externo ficaram dispostos em bancadas inclinadas a $30 \%$, voltados para a direção norte, para maximizar a incidência dos raios solares.

O período de exposição foi de julho a novembro de 2007. As condições climáticas médias durante este período foram de: temperatura máxima $27,6{ }^{\circ} \mathrm{C}$; temperatura mínima $15,5{ }^{\circ} \mathrm{C}$; umidade relativa do ar $63 \%$ e precipitação de $82,3 \mathrm{~mm}$. O experimento foi realizado em atmosfera urbana, na cidade de Campinas, sendo a latitude é $22^{\circ} 48^{\prime} 57^{\prime \prime} \mathrm{S}$, longitude $47^{\circ} 03^{\prime} 33^{\prime \prime} \mathrm{W}$ e altitude $640 \mathrm{~m}$ (CEPAGRI, 2008).

Durante o período de exposição, foram determinadas as velocidades de propagação de onda ultrassônica (VPU) das argamassas e, após o período de exposição, foram determinadas as resistências mecânicas dos corpos de prova à compressão simples.

Na Figura 1, mostram-se os corpos de prova colocados em ambiente interno e externo. 


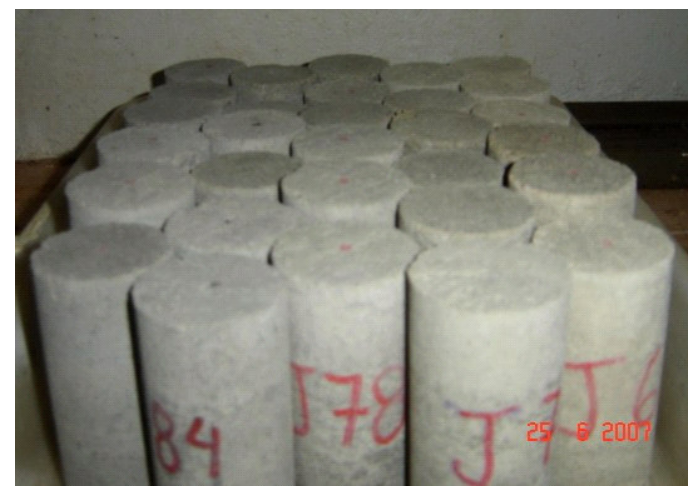

(a)

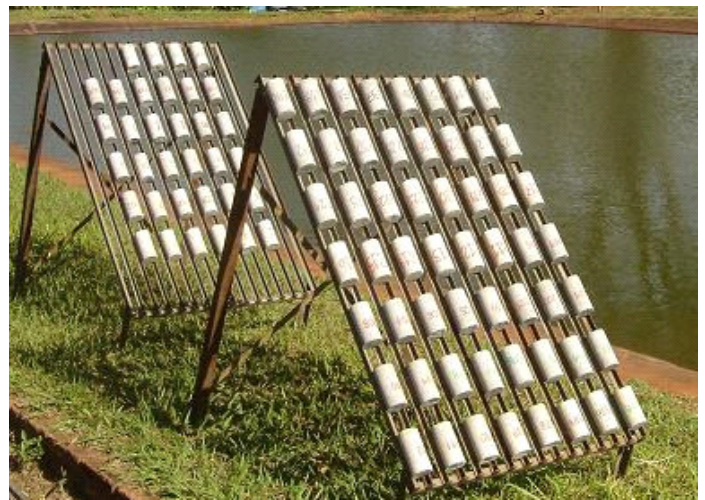

(b)

FIGURA 1. Tipos de exposição: (a) ambiente interno (laboratório); (b) ambiente externo (bancadas). Expositions types: (a) indoor (laboratory); (b) outdoor (stands).

\section{Ensaio não destrutivo - velocidade do pulso ultrassônico (VPU)}

O ensaio de ultrassom foi realizado durante a etapa de endurecimento das misturas, sendo feitas as medições do tempo de propagação da velocidade do pulso ultrassônico (VPU) através dos corpos de prova (BERALDO, 1999). Os corpos de prova foram submetidos a essas medições até o dia de execução do ensaio de compressão simples. Para avaliar o tempo necessário para a propagação da onda ultrassônica, foi utilizado o aparelho Ultrasonic Tester, modelo BP7, da STEINKAMP, dispondo de sensores de seção exponencial com $45 \mathrm{kHz}$ de frequência de ressonância. $\mathrm{O}$ aparelho apresenta sensibilidade de $0,1 \mu$ s na medição do tempo. Para cada mistura, foi avaliada a VPU média, para as diferentes idades, para seis corpos de prova.

\section{Ensaio destrutivo - compressão simples}

Os corpos de prova foram capeados com uma mistura de $75 \%$ de enxofre e $25 \%$ de caulim e, nas idades de ensaio ( 28 dias, quatro meses e cinco meses), foram rompidos em uma máquina universal de ensaios. A determinação da resistência à compressão foi realizada tendo como base a norma NBR 7215 (ABNT, 1996), sendo a tensão calculada dividindo-se a carga de ruptura (N) pela área da seção do corpo de prova $\left(\mathrm{mm}^{2}\right)$, obtendo-se, então, a média de seis repetições.

\section{Análise estatística}

$\mathrm{Na}$ análise estatística deste trabalho, foi utilizado o software estatístico MINITAB, versão 15. Os dados analisados foram referentes às variáveis: tensão de ruptura e velocidade do pulso ultrassônico (VPU). Avaliaram-se os efeitos dos fatores: tipo de exposição (ambiente interno e ambiente externo); tempo de exposição (28 dias; quatro meses e cinco meses); teor de substituição (sem cinza; 5\% de CCA, 10\% de CCA, 15\% de CCA e 20\% de CCA). Os dados coletados foram submetidos à analise de variância, para avaliar os efeitos dos fatores e da interação entre esses fatores. A comparação das médias foi feita por meio do teste de Tukey, a 5\% de significância.

\section{RESULTADOS E DISCUSSÃO}

\section{Caracterização física da CCA residual}

Com base na análise granulométrica a laser, observou-se que a moagem resultou em um material bastante fino, com superfície específica de $3.076 \mathrm{~cm}^{2} \mathrm{~g}^{-1}$, e apenas $0,28 \%$ de material retido na peneira \#200 (de abertura $0,074 \mathrm{~mm}$ ), sendo que $50 \%$ das partículas apresentam diâmetro inferior a $16 \mu \mathrm{m}$ e $10 \%$ das partículas apresentam diâmetro inferior a $3 \mu \mathrm{m}$ (Figura 2). Para que um material possa ser pozolanânico, suas partículas devem apresentar superfície específica maior que $3.000 \mathrm{~cm}^{2} \mathrm{~g}^{-1}$ e/ou diâmetro abaixo de $15 \mu \mathrm{m}$ (JOHN et al., 2003). Desse modo, verifica-se que, em relação ao tamanho de suas partículas, que a CCA poderia ser considerada pozolana. 


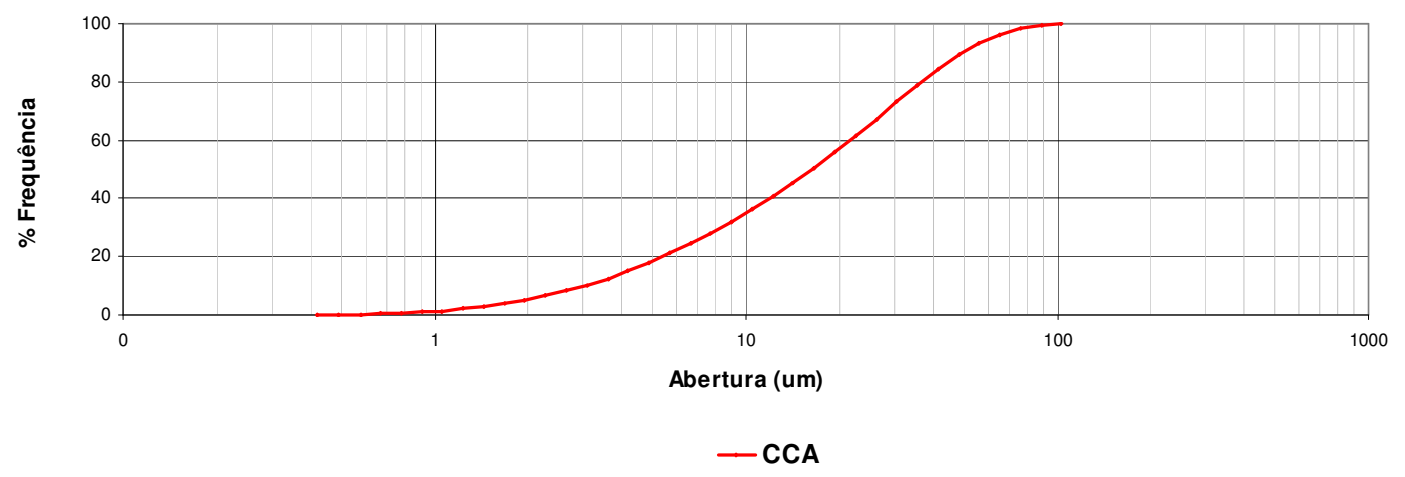

FIGURA 2. Curva granulométrica da CCA residual. Granulometric curve of the residual CCA.

A análise de fluorescência de raios- $\mathrm{X}$ mostrou que a CCA residual é composta de $96,1 \%$ de $\mathrm{SiO}_{2}, 2,24 \%$ de $\mathrm{K}_{2} \mathrm{O}$, e apenas $1,66 \%$ dos óxidos $\left(\mathrm{CaO}, \mathrm{Fe}_{2} \mathrm{O}_{3}, \mathrm{MnO}, \mathrm{Cr}_{2} \mathrm{O}_{3}, \mathrm{ZnO}, \mathrm{Rb}_{2} \mathrm{O}\right.$ e $\left.\mathrm{SrO}\right)$. Ao comparar a composição química dessa cinza com as cinzas estudadas por outros autores, verifica-se uma condição favorável para esta cinza em termos de sua composição química, pois o teor de óxido de silício encontra-se acima do mínimo exigido (44\%) para que seja considerada uma pozolana, segundo CINCOTTO \& KAUPATEZ (1988). Além disso, o teor de $\mathrm{K}_{2} \mathrm{O}$ é inferior a 5\%, encontrando-se dentro do intervalo considerado adequado como pozolana (MEHTA, 1992).

Sabe-se que o carbono não participa nas reações de hidratação e ainda pode afetar o consumo de água de amassamento (JOHN et al., 2003). Portanto, quanto menor o teor de carbono da cinza, melhores serão as reações de hidratação na matriz cimentícia. Na CCA utilizada, o teor de carbono foi de apenas 3\%. De acordo com sua composição química, a CCA poderia ser considerada pozolana.

Na Figura 3, apresenta-se o difratograma da CCA residual, utilizada na produção das argamassas, sendo assinaladas as linhas de difração correspondentes às fases identificadas (cada fase em uma cor distinta). Segundo o difratograma, observa-se um halo vítreo, com picos sobrepostos de fase cristalina da sílica, como é o caso dos picos principais de cristobalita (nas posições $21,9^{\circ} 2 \theta ; 36,1^{\circ} 2 \theta$ ). A cristobalita, o quartzo e a tridimita são diferentes formas cristalinas da sílica, podendo atribuir-se a formação de tais fases cristalinas às condições de queima não controlada do resíduo. Conforme relatado anteriormente, grande parte dos autores afirma que a atividade pozolânica da CCA é caracterizada pela presença de sílica amorfa em misturas com cimento ou cal (MEHTA \& MONTEIRO, 1994; JOHN et al., 2003); no caso desta cinza, embora a mesma apresente um halo de amorficidade, verifica-se a presença de sílica no estado cristalino, o que é um inconveniente para seu uso como material pozolânico.

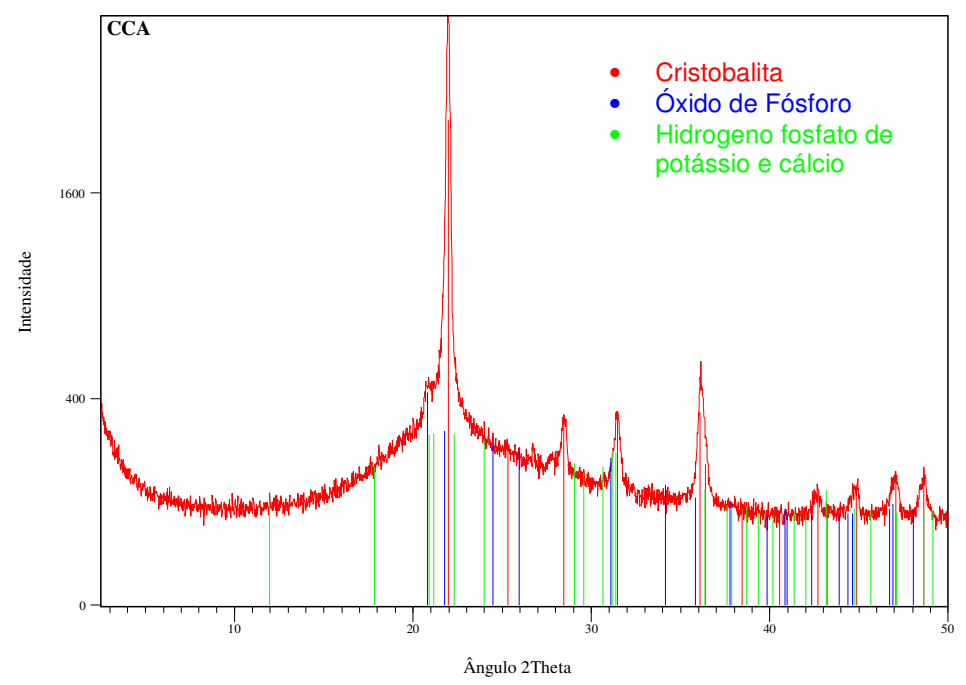

FIGURA 3. Difração de raios-X da CCA residual. X- rays diffraction of residual CCA. 


\section{Avaliação da pozolanicidade da CCA residual}

O teor de substituição do cimento por CCA na realização deste ensaio foi de $35 \%$, de acordo com a NBR 5752 (ABNT, 1992). Os resultados mostram que o índice de atividade pozolânica da argamassa com cinza e cimento Portland foi de apenas 54,44\%, corroborando o resultado do ensaio anterior. A NBR 12653 (ABNT, 1992) estipula um valor mínimo de 75\% para o índice de atividade pozolânica com o cimento Portland. Pode-se concluir, a partir dos resultados obtidos, que a mistura com 35\% de CCA residual não teve um bom desempenho mecânico. Tal fato indica que esta CCA residual não apresenta atividade pozolânica.

\section{Caracterização física e mecânica das argamassas}

Velocidade do pulso ultrassônico através das argamassas (VPU)

Os corpos de prova que ficaram expostos ao ambiente interno (laboratório) passaram por medições diárias do tempo de propagação da VPU, enquanto aqueles expostos ao ambiente externo passaram por medições diárias até os sete primeiros dias e, em seguida, apenas foram realizadas mensurações momentos antes da realização do ensaio de compressão simples. A umidade dos corpos de prova era variável, o que dificultou a avaliação correta da VPU.

Na Figura 4, apresenta-se a curva de VPU referente às argamassas que ficaram em ambiente interno, ensaiadas aos 28 dias; na Figura 5, apresentam-se as curvas de VPU das argamassas em ambiente externo.

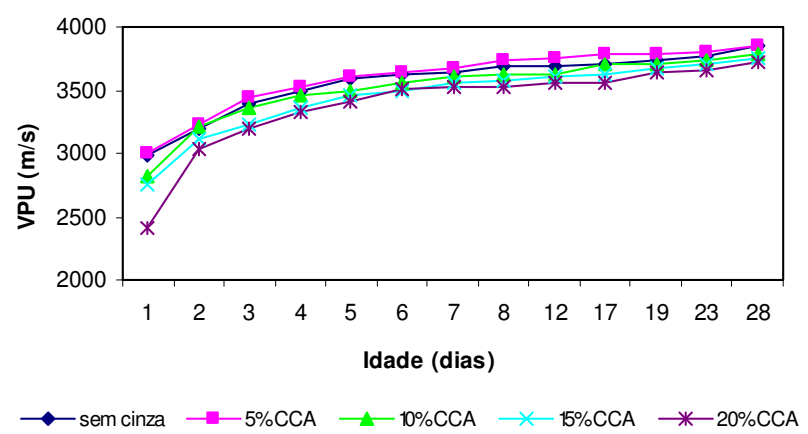

FIGURA 4. VPU nas argamassas ambiente interno - ensaiadas aos 28 dias. VPU in the indoors mortar trialed at 28 days.

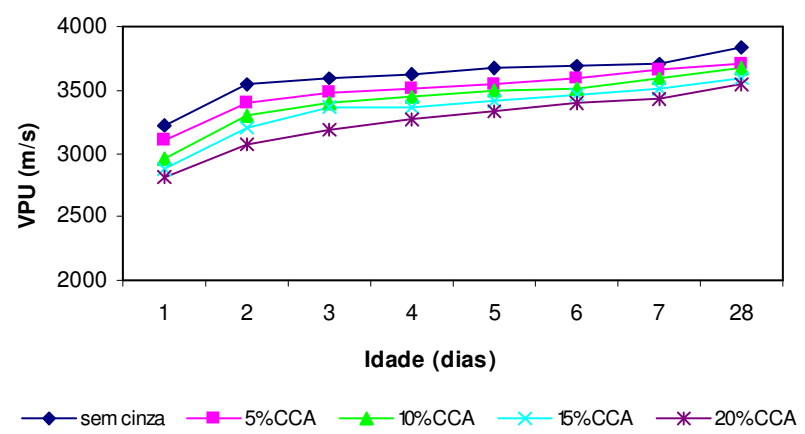

FIGURA 5. VPU nas argamassas ambiente externo - ensaiadas aos 28 dias. VPU in the outdoors mortar trialed at 28 days.

Observa-se que, durante os sete primeiros dias, há uma variação significativa dos valores de VPU e, após essa idade, ocorre tendência à sua estabilização.

Para as argamassas ensaiadas aos quatro e aos cinco meses, pode-se observar que ocorre uma variação mínima dos valores de VPU, em relação à idade de 28 dias, ou seja, não é possível detectar por meio da técnica de ultrassom as mudanças ocorridas no material após um período maior de exposição. Tal fato pode ser observado nas Figuras 6 e 8, para as argamassas que ficaram em ambiente interno e, nas Figuras 7 e 9, para as argamassas que ficaram em ambiente externo.

Para a exposição ao ambiente interno, observou-se de modo geral, que os valores de VPU para as argamassas com teor de $5 \%$ foram próximos ou até mesmo superiores àqueles das argamassas-testemunha (sem cinza). Porém, as argamassas com maiores teores de substituição de CCA (15\% e 20\%) apresentaram as menores médias de VPU. A análise estatística mostrou que a argamassa-testemunha apresenta diferença estatística significativa se comparada às demais argamassas com CCA. Com o aumento do teor de substituição, observa-se decréscimo dos valores de VPU, pois à medida que se faz a substituição de cimento por CCA, a matriz cimentícia tem 
diminuída sua resistência mecânica, indicando, de acordo com esse ensaio, que a CCA não se comporta como uma pozolana.

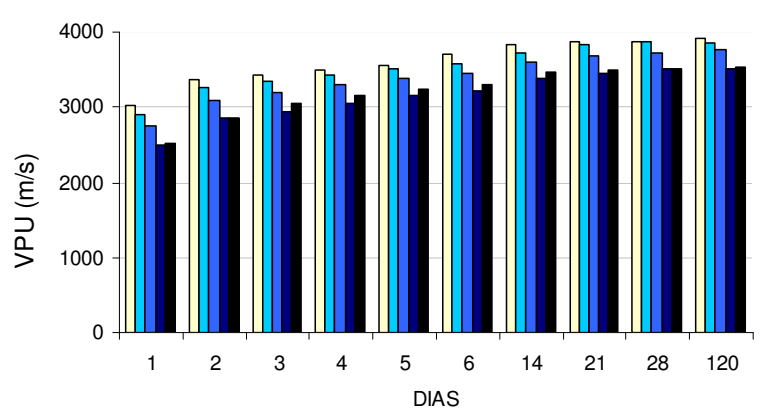

口 sem CCA $\square 5 \%$ CCA $\square 10 \%$ CCA $-15 \%$ CCA $-20 \%$ CCA

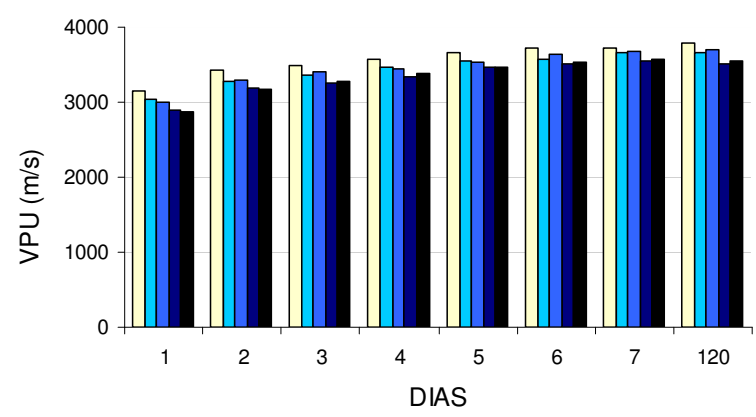

$\square$ sem CCA $\square 5 \%$ CCA $\square$ 10\% CCA $\square 15 \%$ CCA $\square 20 \%$ CCA
FIGURA 6. VPU nas argamassas ambiente interno - ensaiadas aos quatro meses. VPU in the indoors mortar - trialed at four months.

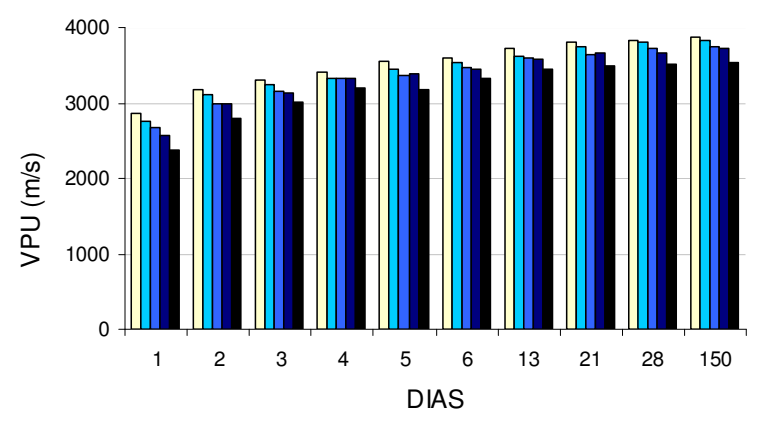

$\square$ sem CCA $\square 5 \%$ CCA $\square 10 \%$ CCA $\square 15 \%$ CCA $\square 20 \%$ CCA
FIGURA 7. VPU nas argamassas ambiente externo - ensaiadas aos quatro meses. VPU in the outdoors mortar - trialed at four months.

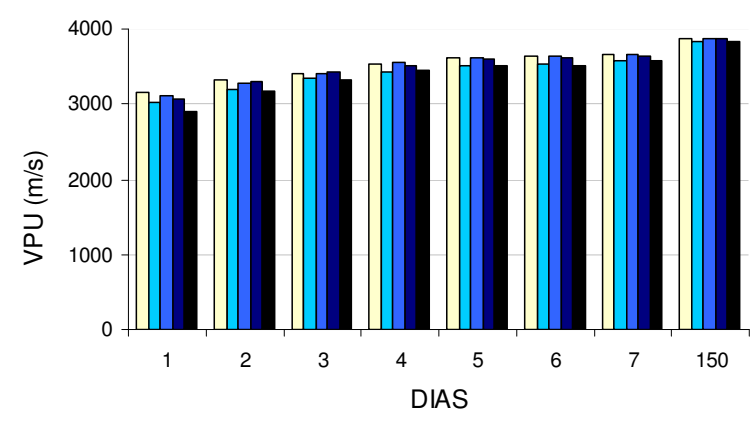

$\square$ sem CCA $\square 5 \%$ CCA $\square 10 \%$ CCA $\square 15 \%$ CCA $\square 20 \%$ CCA
FIGURA 8. VPU nas argamassas ambiente interno - ensaiadas aos cinco meses. VPU in the indoors mortar - trialed at five months.
FIGURA 9. VPU nas argamassas ambiente externo - ensaiadas aos cinco meses. VPU in the outdoors mortar - trialed at five months.

Para a exposição ao ambiente externo, verificou-se novamente que os valores mais elevados de VPU se concentraram nas argamassas-testemunha e naquela com teor de 5\%. Os maiores teores de substituição foram responsáveis pelos menores valores de VPU, com exceção das argamassas ensaiadas aos cinco meses, que apresentaram valores mais elevados de VPU para substituição de $10 \%$ e $15 \%$, com diferença estatisticamente significativa quando comparado aos demais teores. Esse comportamento favorável para as argamassas expostas ao ambiente externo, por um período de cinco meses, deve-se ao fato de que as mesmas passaram por ciclos de umidificação e secagem por um período de tempo maior que as demais argamassas, e dessa forma ocorre melhor fechamento dos poros, por meio do fenômeno da carbonatação. Tais resultados corroboram aqueles obtidos por PIMENTEL (2004).

Houve grande variação de VPU considerando as idades de sete dias em relação ao último dia de exposição. Esses valores estão dentro do que se esperava, visto que a hidratação do cimento CPIII é lenta, ou seja, houve um ganho na resistência do material com a idade. Os corpos de prova que ficaram expostos ao ambiente externo apresentam melhores condições para a propagação da onda de ultrassom, pois houve períodos com grandes precipitações, relançando, dessa forma, as reações de hidratação do cimento e, consequentemente, melhorando a estrutura da matriz. 


\section{Compressão simples - tensão de ruptura}

Na Tabela 1, apresentam-se as médias de resistência à compressão simples com os resultados do teste de Tukey, para as argamassas expostas em ambiente interno, e na Figura 10, apresentam-se as médias de resistência à compressão simples dos diferentes níveis dos fatores "tensão" e "teor" para as mesmas argamassas.

TABELA 1. Médias de resistência à compressão das argamassas em ambiente interno. Resistance averages to the compression of the mortar when it is indoors.

\begin{tabular}{cccccc}
\hline \multirow{5}{*}{ Período } & \multicolumn{5}{c}{ Valores em MPa } \\
\cline { 2 - 5 } & $0 \%$ & $5 \%$ & $10 \%$ & $15 \%$ & $20 \%$ \\
\hline 28 dias & $29,60^{\mathrm{a}}$ & $25,85^{\mathrm{a}}$ & $23,64^{\mathrm{a}}$ & $19,28^{\mathrm{a}}$ & $18,34^{\mathrm{a}}$ \\
Quatro meses & $37,26^{\mathrm{b}}$ & $36,80^{\mathrm{b}}$ & $30,34^{\mathrm{b}}$ & $22,75^{\mathrm{b}}$ & $27,15^{\mathrm{b}}$ \\
Cinco meses & $35,05^{\mathrm{b}}$ & $35,25^{\mathrm{b}}$ & $35,76^{\mathrm{c}}$ & $34,77^{\mathrm{c}}$ & $29,91^{\mathrm{c}}$ \\
\hline
\end{tabular}

Médias na mesma coluna, seguidas da mesma letra, não diferem entre si $(\mathrm{P}>0,05)$, pelo teste de Tukey.

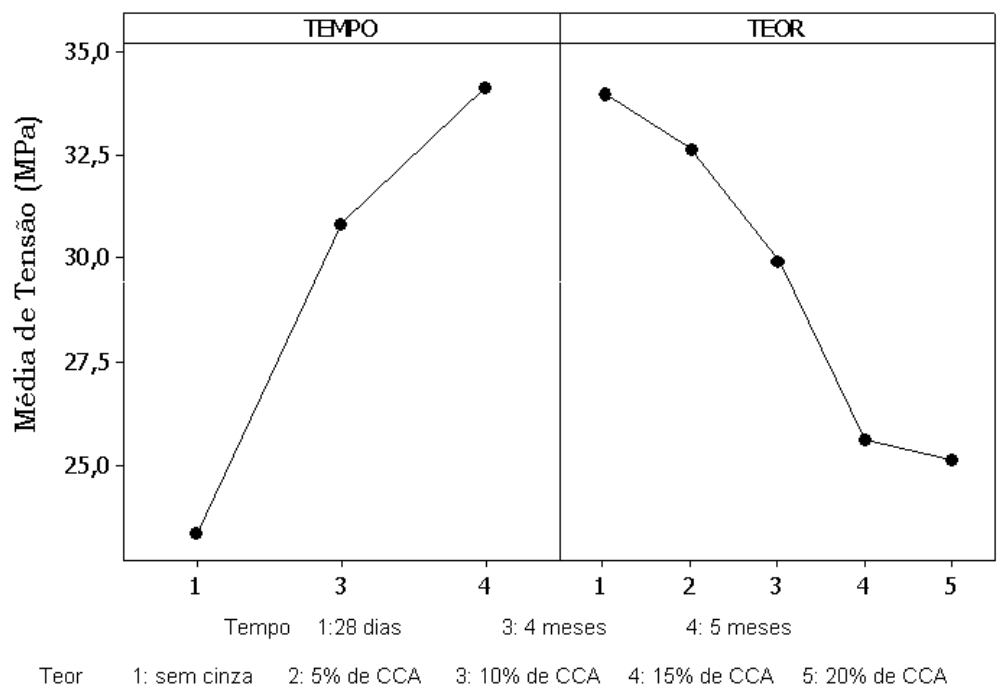

FIGURA 10. Tensão de ruptura para fatores tempo e teor (ambiente interno). Rupture tension for time and content factors (indoors).

Observou-se que, com relação aos valores das médias de tensão para os diferentes tempos de exposição das argamassas em ambiente interno, à medida que aumenta o período de exposição, os valores de tensão tornam-se mais elevados. As argamassas com 10\% de CCA apresentam aumento das médias de tensão à medida que aumentou o período de exposição das mesmas, com diferença estatística entre os períodos; o mesmo ocorre para as argamassas com $15 \%$ e com $20 \%$ de CCA. Logo, pode-se concluir que, com o aumento do tempo de exposição, aumenta-se o valor da tensão para os corpos de prova que ficaram em ambiente interno. Tal fato pode atribuir-se ainda às reações de hidratação do cimento de alto forno CP-III, normalmente mais lentas do que aquela que é observada nos demais cimentos.

Houve diminuição nos valores de tensão à medida que se aumentou o teor de substituição. Entre o teor 1 (sem cinza) e o teor 2 (5\% de CCA), não houve diferença significativa; para o teor 3 (10\% de CCA), também não houve diferença estatística, comparado ao teor 4 (15\% de CCA) e ao 5 (20\% de CCA). O mesmo ocorreu na comparação do teor 4 com o 5.

Na Tabela 2, apresentam-se as médias de resistência à compressão simples com os resultados do teste de Tukey, para as argamassas expostas em ambiente externo, e na Figura 11, apresentam-se 
as médias de resistência à compressão simples dos diferentes níveis dos fatores "tensão" e "teor" para as mesmas argamassas.

TABELA 2. Médias de resistência à compressão das argamassas em ambiente externo. Resistance averages to the compression of the mortar when it is outdoors.

\begin{tabular}{cccccc}
\hline & \multicolumn{5}{c}{ Valores em MPa } \\
\hline \multirow{2}{*}{ Período } & $0 \%$ & $5 \%$ & $10 \%$ & $15 \%$ & $20 \%$ \\
\cline { 2 - 5 } & $26,62^{\mathrm{a}}$ & $19,21^{\mathrm{a}}$ & $23,94^{\mathrm{a}}$ & $28,02^{\mathrm{a}}$ & $24,86^{\mathrm{a}}$ \\
Quatro meses & $32,60^{\mathrm{b}}$ & $36,40^{\mathrm{b}}$ & $32,22^{\mathrm{b}}$ & $27,51^{\mathrm{a}}$ & $31,27^{\mathrm{b}}$ \\
Cinco meses & $34,00^{\mathrm{b}}$ & $26,08^{\mathrm{c}}$ & $32,48^{\mathrm{b}}$ & $33,24^{\mathrm{b}}$ & $30,44^{\mathrm{b}}$ \\
\hline
\end{tabular}

Médias na mesma coluna, seguidas da mesma letra, não diferem entre si $(\mathrm{P}>0,05)$, pelo teste de Tukey.

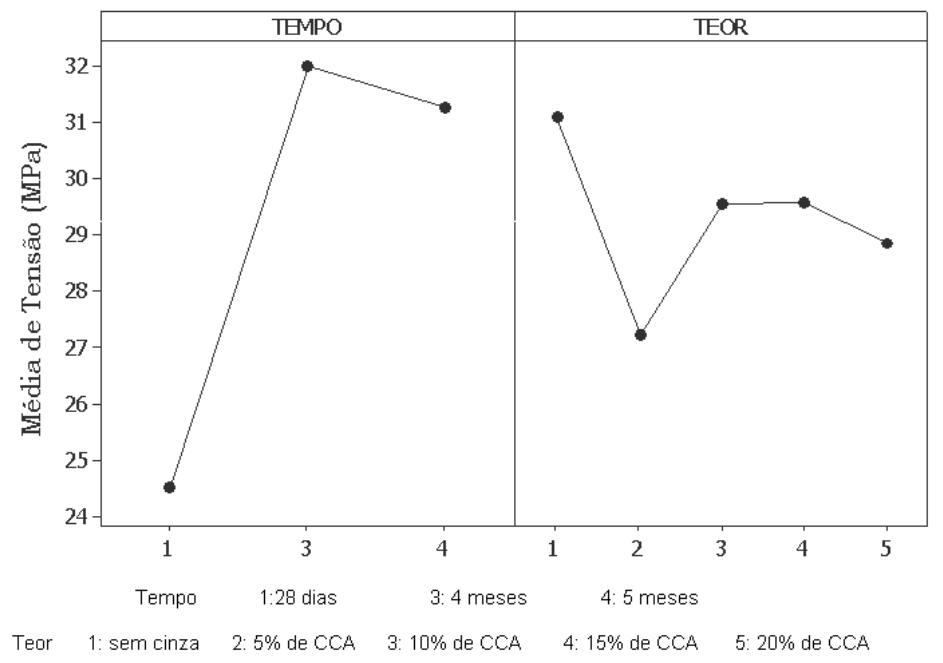

FIGURA 11. Tensão de ruptura para fatores tempo e teor (ambiente externo). Rupture tension for time and content factors (outdoors).

Para as argamassas que ficaram expostas ao ambiente externo, observou-se que os valores de tensão foram inferiores para os corpos de prova ensaiados aos 28 dias quando comparados aos corpos de prova ensaiados aos quatro meses e aos cinco meses. Esses resultados já eram esperados, pois materiais à base de cimento CPIII apresentam maiores valores de tensão para idades mais avançadas.

Para as argamassas com 10\% de CCA, 20\% de CCA e testemunha, não houve diferença estatística entre os corpos de prova ensaiados aos quatro e aos cinco meses.

No entanto, para o fator "teor", houve um grande decréscimo na média da tensão para o teor 2 (5\% de CCA), que mostrou diferença estatística se comparado ao teor 1 (testemunha). Essa variabilidade pode ter ocorrido durante o processo de produção dos corpos de prova, em razão da má compactação ou devido a problemas ocorridos durante o capeamento. Já se esperava que, à medida que aumentasse o teor de CCA, houvesse uma diminuição na tensão; entretanto, os valores referentes ao teor 2 (5\% de CCA) mostraram-se inferiores aos teores 3 (10\% de CCA), 4 (15\% de CCA) e 5 ( $20 \%$ de CCA), com diminuição de $5 \%$ nas médias de tensão.

\section{CONCLUSÕES}

A CCA residual utilizada apresentou em sua composição química 96\% de óxido de silício e, portanto, apresenta condições favoráveis para ser considerada como pozolana. Entretanto, a análise de difração de raios- $X$ indicou que se trata de uma cinza cristalina (portanto, não reativa), embora apresente um halo com certo grau de amorfismo. 
A avaliação de pozolanicidade da cinza mostrou que as argamassas produzidas com $35 \%$ de CCA, em substituição ao cimento, não atingiram a resistência mínima estipulada pela NBR 12653. Desse modo, concluiu-se que a CCA residual utilizada neste trabalho pode fazer parte da matriz cimentícia apenas como material fino de preenchimento (filler), porém não como um material pozolânico.

A caracterização mecânica das argamassas mostrou que tanto para os corpos de prova que ficaram expostos em ambiente interno, quanto àqueles que ficaram em ambiente externo, à medida que se aumentou o tempo de exposição, houve também um aumento na resistência à compressão. Argamassas com 5\% de CCA, que ficaram em ambiente interno, apresentaram resistência à compressão similar à da testemunha.

Para os valores de VPU, observou-se que, quanto ao tempo de exposição, os corpos de prova que ficaram expostos por mais tempo (cinco meses) apresentaram as maiores médias de VPU. Quanto ao teor de substituição, à medida que aumentou o teor, menores foram os valores de média de VPU, com exceção para a argamassa com 5\% de CCA.

\section{AGRADECIMENTOS}

Ao CNPq, pela bolsa concedida, e à Faculdade de Engenharia Agrícola da Universidade Estadual de Campinas.

\section{REFERÊNCIAS}

ASSOCIAÇÃO BRASILEIRA DE NORMAS TÉCNICAS - ABNT. NBR 5735 - Cimento Portland de Alto Forno: especificação. Rio de Janeiro, 1991. 10 p.

NBR 5752 - Materiais pozolânicos: determinação de atividade pozolânica com cimento Portland - Índice de Atividade Pozolânica com cimento. Método de ensaio. Rio de Janeiro, 1992. $3 \mathrm{p}$.

NBR 7215 - Cimento Portland: determinação da resistência à compressão, método de ensaio. Rio de Janeiro, 1996. 8 p. NBR 12653 - Materiais pozolânicos: especificação. Rio de Janeiro, 1992. 3 p.

BERALDO A.L. Ultrasonic speed wave: cure type influence on wood-cement composite compression strength. In: INTERNATIONAL SYMPOSIUM ON NON DESTRUCTIVE TESTING CONTRIBUTION TO THE INFRASTRUCTURE SAFETY SYSTEMS, 21., 1999, Torres. Procedings... Santa Maria: UFMS, 1999. p.86-90.

CENTRO DE PESQUISAS METEOROLÓGICAS E CLIMÁTICAS APLICADAS À AGRICULTURA - CEPAGRI. Clima de Campinas. Disponível em $<$ http://www.cepagri.unicamp.br>. Acesso em: jan 2008.

CINCOTTO, M.A.; KAUPATEZ, R.Z. Seleção de materiais quanto à atividade pozolânica. In: INSTITUTO DE PESQUISAS TECNOLÓGICAS - IPT. Tecnologia de edificações. São Paulo: Pini, 1988. p.23-26.

DELLA, V.P.; KÜHN, I.; HOTZA, D. Caracterização de cinza de casca de arroz para uso como matéria-prima na fabricação de refratários de sílica. Química Nova, São Paulo, v.24, n.6, p.778-782, 2001.

INSTITUTO BRASILEIRO DE GEOGRAFIA E ESTATÍSTICA - IBGE. Produção agrícola nacional. Disponível em: <http: //www.ibge.com.Br>. Acesso em: 20 jul. 2007.

JOHN, V.M.; CINCOTTO, M.A.; DA SILVA, M.G. Cinzas e Aglomerantes Alternativos. In: FREIRE, W.J.; LUDOVICO, A. Tecnologia e materiais alternativos de construção. Campinas: Editora da UNICAMP, 2003. p.145-190. 
MEHTA, P.K. Rice husk ash: a unique supplementary cementing material. In: MALHOTRA, V.M. (Ed.). Advances in concrete technology. Otawa: Canmet, 1992. p.403-431.

MEHTA, P.K.; MONTEIRO, P.J.M. Concreto, estruturas, propriedades e materiais. São Paulo: Pini, 1994. 574 p.

NAIR, D.G.; JAGADISH, K.S.; FRAAIJ, A. Reactive pozzolanas from rice husk ash: an alternative to cement for rural housing. Cement and Concrete Research, New York, v.36, n.6, p.1.062-1.071, 2006.

PIMENTEL, L.L. Durabilidade de argamassas modificadas por polímeros e reforçadas com fibras vegetais. 2004. 124 f. Tese (Doutorado em Engenharia Agrícola) - Faculdade de Engenharia Agrícola, Universidade Estadual de Campinas, Campinas, 2004.

POUEY, M.T.; DAL MOLIN, D.C.C.; BERGMANN, C.P. Avaliação de diferentes processos de moagem de cinzas de casca de arroz residuais com diferentes características mineralógicas através do Índice de Atividade Pozolânica. In: CONGRESSO BRASILEIRO DE CONCRETO, 49., 2007. Bento Gonçalves. Anais... 1 CD-ROM.

ZUCCO, L.L. Avaliação do comportamento físico-quimico-mecânico de misturas cimento-cinzacasca de arroz por meio de corpos de prova cilíndricos e placas prensadas. 2007. $422 \mathrm{f}$. Tese (Doutorado em Engenharia Agrícola - Construções Rurais) - Faculdade de Engenharia Agrícola, Universidade Estadual de Campinas, 2007. 